\title{
O Foro por Prerrogativa de Função no Estado Democrático de Direito e os Possíveis Prejuízos Às Investigações Criminais
}

\author{
ANderson BurKe ${ }^{1}$ \\ Américo Bedê Freire Júnior ${ }^{2}$
}

\begin{abstract}
Resumo
O foro por prerrogativa de função também conhecido por foro privilegiado vem passando por uma série de debates em virtude de suas repercussões que decorrem da proteção conferida pela Constituição a diversos agentes políticos que possuem certo poder e autoridade em nosso país. Referida garantia constitucional positivada no contexto pós ditadura em 1988, se justificou pela preservação do Estado Democrático de Direito ao se conferir um juízo em tese mais qualificado ao agente detentor do cargo, assim como para que tenha liberdade e independência em sua atuação funcional, blindando-o contra perseguições políticas. Neste contexto, buscaremos estudar o instituto do inquérito policial, este instrumento que materializa o curso das investigações criminais, para demonstrar sua finalidade ao Estado Democrático de Direito, assim como para se realizar a verificação sobre os efeitos que o foro privilegiado gera sobre a elucidação dos indícios de autoria e prova de materialidade de algum crime. Portanto, o que buscamos na pesquisa é concluir se o instituto do foro por prerrogativa de função está adequado ao momento político e social vivenciado no Brasil, bem como analisar se a mencionada garantia positivada na Constituição brasileira provoca danos às investigações criminais e consequentemente ao Estado Democrático de Direito.
\end{abstract}

1 Aluno regular do mestrado em Direito e Garantias Fundamentais pela Faculdade de Direito de Vitória (FDV); Professor Assistente no curso de graduação em Direito da Faculdade de Direito de Vitória (FDV); Professor Titular no curso de graduação em Direito do Centro de Ensino Superior de Vitória (CESV) e Advogado. Especialista em Ciências Criminais, Direito Constitucional e Direito Tributário.

2 Professor da graduação e da Pós-Graduação stricto sensu da Faculdade de Direito de Vitória (FDV) e Juiz Federal. Doutor e Mestre em Direitos e Garantias Fundamentais pela Faculdade de Direito de Vitória (FDV). 
Palavras-Chave: Foro Por Prerrogativa de Função. Foro Privilegiado. Estado Democrático de Direito. Inquérito Policial. Investigação Criminal. Direitos e Garantias Fundamentais. Direito Constitucional. Direito Processual Penal.

\begin{abstract}
The forum by function prerogative also known as privileged forum has been going through a series of debates because of its repercussions stemming from the protection granted by the Constitution to various political agents who have certain power and authority in our country. The aforementioned constitutional guarantee recognised in the postdictatorship context in 1988, was justified by the preservation of the democratic State by the rule of law by granting a judgment in more qualified thesis to the agent holding the position, as well as to have freedom and independence in its functional performance, against political persecution. In this context, we will seek to study the police investigation institute, this instrument that materializes the course of criminal investigations, to demonstrate its purpose to the democratic State by the rule of law, as well as to verify the effects that the privileged forum generates on the elucidation of the evidence of authorship and proof of materiality of any crime. Therefore, what we seek in the research is to conclude whether the institute of the forum by prerogative of function is adequate to the political and social moment experienced in Brazil, as well as to analyze if the mentioned positive guarantee in the Brazilian Constitution causes damages to the criminal investigations and consequently to the democratic State by the rule of law.
\end{abstract}

Palavras-Chave: Forum by prerogative of function. Democratic State by the rule of law. Policial Inquiry. Criminal investigation. Fundamental Rights and Guarantees. Constitucional Law

\title{
INTRODUÇÃo
}

Investigaremos o instituto do foro por prerrogativa de função, também conhecido por foro privilegiado, este positivado em nossa Constituição e que tem por finalidade a tutela de autoridades detentora de cargos considerados de importância por 
nosso constituinte e que por essa condição são possuidores da mencionada garantia constitucional que visa conferir um juízo em tese mais qualificado. Além da finalidade dita acima, também há a possível blindagem de referidas autoridades contra arbitrariedades e intervenções em seus exercícios funcionais.

Logo em seguida, verificaremos a justificativa e o motivo pelo qual o constituinte positivou o foro por prerrogativa de função em nossa Constituição, à luz do princípio do Estado Democrático de Direito positivado no art. $1^{\mathrm{o}}$, da Constituição da República Federativa do Brasil.

Feita a relação buscada no parágrafo acima, estudaremos profundamente o instituto do Estado Democrático de Direito, no intuito de esclarecê-lo e se verificar como ele se materializa no atual momento político e social vivenciado no Brasil, haja vista ser esta uma disposição que foi positivada em 1988 e, possivelmente, tendo existido uma razão para tanto no momento passado.

Para chegarmos ao problema central da pesquisa, precisaremos explorar e elucidar o instituto do inquérito policial, este pertinente a instrumentalizar as investigações criminais das autoridades detentoras do foro por prerrogativa, no intuito de compreender se referido instituto possui alguma finalidade ligada aos anseios do Estado Democrático de Direito e quais são as consequências que sofre com as restrições impostas pelo foro.

Assim, com o objetivo de preservar os direitos e garantias fundamentais previstos na CRFB e as regras do Código de Processo Penal, é de suma importância que se responda a pergunta: o foro por prerrogativa de função enseja danos às investigações criminais sobre as autoridades tuteladas pela regra constitucional e por consequência causa violação ao Estado Democrático de Direito diante do atual momento político e social vivenciado no Brasil? 


\section{O Foro por Prerrogativa de Função e sua Razão Constitucional}

O foro por prerrogativa de função existe em nossa Constituição em alguns de seus dispositivos, com destaque à literatura dos artigos 53, § 1; 102, I, “b” e "c"; 105, I, “a”; 29, X; 96, III; e 108, I, “a”. Estes dispositivos previstos na Constituição da República Federativa do Brasil de 1988 reserva o julgamento de deputados, senadores, presidentes, governadores, prefeitos, juízes, desembargadores, dentre outras autoridades políticas, que estão no exercício de suas funções, à jurisdição de órgãos colegiados que são compostos por magistrados que atuam em grau superior de julgamento.

Para compreendermos a razão do instituto, na intenção de se alcançar o espírito do constituinte de 1988, importante o esclarecimento sobre o momento político vivenciado no Brasil, o que fez o professor Kildare Gonçalves Carvalho (2008, p. 244), o qual demonstra que:

A quarta fase é a do período liberal-social, abrangendo as Constituições de 1946 e a de 1988, com o hiato das de 1967/1969, em que houve retorno ao modelo estatizante e centralizador. Houve expressiva produção teórica, sob o influxo da Constituição de 1946.

Notou-se, portanto, que o país estava num período político liberal-social conhecido como a quarta fase do constitucionalismo brasileiro. No referido período, nomeado por "liberalsocial" pelo autor, existiu a busca de consagração de direitos e garantias individuais pertinentes ao estado de bem-estar social que englobava os direitos de $1^{\text {a }}$ (primeira) e $2^{\underline{a}}$ (segunda) geração.

Importante acrescentar que este contexto foi antecedido, conforme alertado pelo autor citado acima, por um período estatizante e centralizador, no que diz respeito ao período que antecedeu a Constituição de 1988. 
Ainda sobre o contexto histórico da Constituição Cidadã, temos a explicação de Ingo Wolfgang Sarlet, Luiz Guilherme Marinoni e Daniel Mitidiero (2017, p. 251), os quais revelam que:

As origens do movimento que culminou na edição da EC 26/1985, e da correlata convocação da Assembleia Nacional Constituinte de 1987/1988, remontam à transição do regime ditatorial de 1964, em direção à "abertura política", iniciada ainda no Governo Ernesto Geisel e consolidada durante o Governo do General João Batista de Figueiredo, que propiciou a abertura do sistema partidário e promoveu a aprovação da Lei de Anistia, num contexto social e político marcado por um crescimento das reinvindicações de diversos setores da sociedade e uma articulação da sociedade civil, sob a direção de instituições representativas, tais como a OAB, a CNBB e as principais entidades sindicais. [...]

No âmbito do contexto liberal-social citado, o qual visa a consagração de direitos e garantias fundamentais de $1^{\text {a }}$ (primeira) e 2 ${ }^{\text {a }}$ (segunda) geração, temos também a saída de um regime ditatorial conhecido por diversas arbitrariedades e perseguições políticas, para um regime democrático visado pelo Estado Democrático de Direito positivado no art. $1^{\underline{0}}$ da Constituição brasileira, como um princípio a ser respeitado pela nossa ordem jurídica, política e social.

Nessa transição de um regime ditatorial para o Estado Democrático de Direito estabelecido pela Assembleia Nacional Constituinte de 1987/1988, entra em debate o instituto que diz respeito à nossa investigação, qual seja o foro por prerrogativa de função, o qual também é conhecido por "foro privilegiado". No que tange ao instituto, Uadi Lâmego Bulos (2017, p. 1128) leciona que:

A prerrogativa de foro em razão da função é um corolário da imunidade propriamente dita, ensejando o monopólio de jurisdição da Corte Suprema. 


\section{$[\ldots]$}

Assim, deputados e senadores, desde a expedição do diploma, só podem ser submetidos a julgamento no Supremo Tribunal Federal (CF, art. 53, § 1ํㅡㄴ com redação dada pela EC. a. 35/2001, cuja novidade ficou por conta da frase "desde a expedição do diploma").

Constata-se, portanto, que o foro por prerrogativa de função representa um corolário da imunidade das autoridades políticas, uma vez que é monopólio do STF a jurisdição sobre, por exemplo, deputados federais e senadores, haja vista que desde a expedição do diploma só poderão ser submetidos a julgamento pelo tribunal previsto no dispositivo constitucional.

Pelo o que foi exposto acima, vislumbrou-se que a prerrogativa de foro consiste numa reserva de jurisdição a determinados tribunais para a análise de crimes cometidos por deputados e senadores, estes que ficam submetidos ao monopólio do Supremo Tribunal Federal.

Conclui-se que o instituto aqui estudado se revelou como uma garantia constitucional pós período ditatorial. Teve a finalidade de proteger as autoridades contra arbitrariedades jurídicas de cunho político, no intuito de preservar a liberdade necessária para o exercício da função pública, para a consagração do recém conquistado (1988) Estado Democrático de Direito.

Ainda com a finalidade de explorar o instituto em apreço, temos o posicionamento do autor André Ramos Tavares (2017, p. 1005) o qual relata que:

Deputados e Senadores só serão submetidos a julgamento penal perante a Corte Suprema, vale dizer, perante o Supremo Tribunal Federal. É o que determina, atualmente, o art. 53, § $1^{\circ}$.

Trata-se, pois, do que se denomina, processualmente, privilégio de foro, ou seja, os deputados e senadores não serão 
submetidos aos tribunais ou juízos comuns, aos quais estão jungidos os demais cidadãos.

Além da informação já consolidada de que deputados e senadores somente poderão ser submetidos a julgamento perante o STF após a expedição do diploma, necessário se faz pontuar que é uma garantia constitucional de natureza processual penal, que retira dos juízos comuns a investigação, processamento e julgamento das autoridades elencadas no texto constitucional.

No que tange especificamente ao tratamento dos inquéritos policiais à luz da garantia aqui trabalhada, Gilmar Ferreira Mendes e Paulo Gustavo Gonet Branco (2016, p. 972) ilustram que:

O congressista é processado criminalmente, durante o mandato, pelo STF.

Mesmo os inquéritos policiais devem correr no Supremo Tribunal. Se estão tendo curso em outra instância, cabe reclamação para obviar a usurpação de competência. A competência do STF é abrangente de todas as modalidades de infrações penais, estendendo-se aos delitos eleitorais e alcançando, até mesmo, as próprias contravenções penais. O foro especial prevalece sobre a competência do júri também prevista constitucionalmente.

Pelo o que foi explicado acima, a instauração e os atos decisórios dos inquéritos policiais também são de monopólio de jurisdição do tribunal escolhido pela Constituição para julgar a autoridade detentora do foro privilegiado. No caso citado pelos autores, os procedimentos administrativos de investigação que versarem sobre possíveis crimes cometidos por deputados e senadores, obrigatoriamente, devem tramitar no Supremo Tribunal Federal.

Especificamente sobre o espírito do instituto do foro por prerrogativa de função, rica é a análise realizada por Marcelo Semer apud Guilherme de Souza Nucci (2017, p. 216/217), conforme se verifica na transcrição a seguir: 
[...] o foro privilegiado para julgamentos criminais de autoridades é outra desigualdade que ainda permanece. Reproduzimos, com pequenas variações, a regra antiga de que fidalgos de grandes estados e poder somente seriam presos por mandados do Rei. É um típico caso em que se outorga maior valor à noção de autoridade do que ao princípio de isonomia, com a diferença de que hoje a igualdade é um dos pilares da Constituição. (...) Competência processual não se deve medir por uma ótica militar ou por estrato social. Autoridades que cometem crimes devem ser julgadas como quaisquer pessoas, pois deixam de se revestir do cargo quando praticam atos irregulares. (...) $O$ foro privilegiado, tal qual a prisão especial, é herança de uma legislação elitista, que muito se compatibilizou com regimes baseados na força e no prestígio da autoridade.

É dito que o foro por prerrogativa de função revela uma desigualdade na sociedade brasileira, uma vez que é reproduzida de modo bem aproximado à antiga regra de que os poderosos fidalgos somente poderiam ser presos por mandados do Rei, violando-se a isonomia pretendida pela Constituição brasileira. É na verdade uma herança legal elitista que habitou antigos regimes baseados na força e no prestígio da autoridade. Defende-se que as autoridades devem ser julgadas como pessoas comuns, pois quando praticam atos ilícitos deixam de se revestir do cargo que ocupam.

Embora pertinente a crítica feita acima, não podemos nos afastar do espírito do constituinte em blindar as autoridades de perseguições jurídicas de cunho político vivenciadas no período ditatorial, no momento da promulgação da Constituição de 1988, esta que busca a plenitude de suas instituições políticas.

O que analisaremos nos capítulos seguintes é se o contexto aqui alertado no qual vivia o constituinte na positivação do foro por prerrogativa de função, permanece nos dias atuais, bem como se o instituto está sendo desvirtuado de sua função em preservar a salubridade do Estado Democrático de Direito. 


\section{O Estado Democrático de Direito Previsto na Constituição da República Federativa do Brasil DE 1988}

Para a continuidade da presente investigação, é de suma importância compreendermos o Estado Democrático de Direito positivado na Constituição da República Federativa do Brasil, essa que igualmente fez a previsão do foro por prerrogativa de função em seu texto.

Relativamente ao instituto aqui trabalhado, Manoel Jorge e Silva Neto (2010, p. 266) explica que:

Finalmente, "Estado Democrático de Direito" outro significado não tem que Estado de Direito e de Justiça Social.

O acréscimo da expressão "democrático" ocorreu a partir da Constituição de 1988 e impinge nova compreensão do Estado brasileiro, porque, conforme acentua Miguel Reale, "pela leitura dos Anais da Constituinte infere-se que não foi julgado bastante dizer-se que somente é legítimo o Estado constituído de conformidade com o Direito e atuante na forma do Direito, porquanto se quis deixar bem claro que o Estado deve ter origem e finalidade de acordo com o Direito manifestado livre e originariamente pelo próprio povo, excluída, por exemplo, a hipótese de adesão a uma Constituição outorgada por uma autoridade qualquer, civil ou militar, por mais que ela consagre os princípios democráticos".

Poder-se-á acrescentar que o adjetivo "Democrático" pode também indicar o propósito de passar-se de um Estado de Direito, meramente formal, a um Estado de Direito e de Justiça Social, isto é, instaurado concretamente com base nos valores fundantes da comunidade. "Estado Democrático de Direito", nessa linha de pensamento equivaleria, em última análise, a "Estado de Direito e de Justiça Social.

É explicado pelo autor que o Estado Democrático de Direito reflete diretamente o Estado de Direito e de Justiça Social, 
uma vez que somente será legítimo se estiver em conformidade e em exercício com o Direito que foi estabelecido livre e originariamente pelo povo, evitando-se, rigorosamente, a adesão a qualquer regime diferente daquele pactuado na Constituição, qual seja o democrático, que representa o poder do povo.

Ao desenvolver tais ideias, o Ministro Alexandre de Moraes (2015, p. 6) observa que:

O Estado Democrático de Direito, caracterizador do Estado Constitucional, significa que o Estado se rege por normas democráticas, com eleições livres, periódicas, e pelo povo, bem como o respeito das autoridades públicas aos direitos e garantias fundamentais e proclamado, por exemplo, no caput do art. $1^{o}$ da Constituição da República Federativa do Brasil, que adotou, igualmente, em seu parágrafo único, o denominado princípio democrático ao afirmar que "todo o poder emana do povo, que o exerce por meio de representantes eleitos ou diretamente, nos termos desta Constituição" [...]

O Estado Constitucional, portanto, é mais do que o Estado de Direito, é também o Estado Democrático, introduzido no constitucionalismo como garantia de legitimação e limitação do poder

Primeiramente, verifica-se que o Estado Democrático de Direito é o caracterizador do Estado Constitucional, haja vista que é regido por normas democráticas através de eleições periódicas, pelo povo, e, no que interessa à nossa pesquisa, no respeito das autoridades públicas aos direitos e garantias fundamentais. O instituto representa como seu corolário garantia de legitimação e limitação do poder estatal.

Diante do contexto político já denunciado no momento da promulgação da Constituição de 1988, o constituinte em prol da plenitude do Estado Democrático de Direito, buscou legitimar o poder e liberdade de autoridades, assim como limitar o mesmo poder e liberdade dessas autoridades no que tange às investiga- 
ções, processos e julgamentos criminais, através da garantia do foro por prerrogativa de função.

Tal constatação se confirma pela leitura realizada ao doutrinador Bernardo Gonçalves Fernanes (2011, p. 209), o qual afirma que é Fato que democracia hoje não se dá apenas pela possibilidade de escolha dos atores políticos, mas inclui ainda uma proteção constitucional que afirma: a superioridade da Constituição; a existência de direitos fundamentais; da legalidade das ações estatais; um sistema de garantias jurídicas e processuais.

Entende-se que a democracia, pilar do Estado Democrático de Direito, não se materializa simplesmente pela possibilidade de escolha dos atores políticos, mas fundamentalmente por uma proteção constitucional que envolva sistematicamente a superioridade da Constituição, a existência de direitos fundamentais, a legalidade de ações estatais e um sistema de garantias jurídicas e processuais.

Portanto, o Estado Democrático de Direito depende de garantias jurídicas e processuais que confiram a superioridade da Constituição em nosso país, o que tem como ponto de partida a proteção de autoridades contra perseguições indevidas, condição esta que justifica o nascimento do foro privilegiado.

Além disso, o Estado, igualmente para assegurar a existência de direitos fundamentais, deve prevenir e reprimir condutas criminosas através do direito penal, o que é tratado por Muñoz Conde apud Cezar Roberto Bitencourt (2016, p. 599):

[...] sem a sanção do comportamento social desviado (delito), a convizência humana em uma sociedade tão complexa e altamente tecnificada como a sociedade moderna seria impossível. A pena (ou, quando for o caso, a medida de segurança) é uma condição indispensável para o funcionamento dos sistemas sociais de convizência. 
Para a possibilidade do funcionamento dos sistemas sociais de convivência de interesse do Estado Democrático de Direito, através da prevenção e repressão de crimes, inclusive aqueles cometidos por autoridades, o primeiro passo instrumental para o início de uma investigação da ocorrência de um crime é a instauração de um inquérito policial, este outro instituto de suma relevância que será objeto de investigação agora no próximo capítulo.

\section{O Inquérito Policial e sua Finalidade no Estado Democrático de Direito}

Vamos agora analisar o instituto do inquérito policial como um instrumento pertinente aos interesses e objetivos do Estado Democrático de Direito positivado no art. $1^{\circ}$ da CRFB.

No que diz respeito ao instituto do inquérito policial, o doutrinador Renato Brasileiro de Lima (2014, p. 108) explica que:

Trata-se de um procedimento de natureza instrumental, porquanto se destina a esclarecer os fatos delituosos relatados na notícia de crime, fornecendo subsídios para o prosseguimento ou o arquivamento da persecução penal. De seu caráter instrumental sobressai sua dupla função: a) preservadora: a existência prévia de um inquérito policial inibe a instauração de um processo penal infundado, temerário, resguardando a liberdade do inocente e evitando custos desnecessários para o Estado; b) preparatória: fornece elementos de informação para que o titular da ação penal ingresse em juízo, além de acautelar meios de prova que poderiam desaparecer com o decurso do tempo.

Verifica-se pelas lições acima que o inquérito policial possui uma dupla função, quais sejam a preservadora e a preparatória. A preservadora visa resguardar a liberdade do inocente, evitando-se um processo penal despótico e sem provas. Já a preparatória visa buscar elementos probatórios para garantir ao Estado o seu direito 
de punir, evitando-se que eventuais elementos indiciários desapareçam com o decurso do tempo, quais sejam os indícios de autoria e prova de materialidade da ocorrência do delito.

Ainda sobre o inquérito policial, o professor Eugênio Pacelli Oliveira (2016, p. 32) traz em sua doutrina que:

Nos passos, então, de uma formulação - menos sofisticada, é certo - mais ajustada aos propósitos nacionais, o que inclui e exige uma atenção às deficiências históricas de nosso desenvolvimento, ficamos com a noção de Estado Democrático de Direito orientada pela necessidade de reconhecimento e de afirmação da prevalência dos direitos fundamentais, não só como meta da política social, mas como critério de interpretação do Direito, e, de modo especial, do Direito Penal e do Direito Processual Penal. E isso não só é possível, como necessário, na medida em que a intervenção penal vem explicitamente admitida no texto constitucional (ver, por exemplo, referência expressa aos crimes de racismo, de tortura, de drogas e entorpecentes, aos crimes hediondos, bem como à garantia processual da ação privada subsidiária da pública, no caso de inércia do Ministério Público - art. 5o, XLII, XLIII, LIX, CF)

Pelo o que foi exposto, entende-se que a interpretação do Direito Penal e Processual Penal, deve atender à afirmação e reconhecimento dos direitos fundamentais, com o objetivo de se respeitar o instituto do Estado Democrático de Direito. É pacífico que é uma garantia fundamental do Estado a investigação de crimes, quanto mais de agentes políticos responsáveis por decisões que afetam toda a coletividade.

Deste modo, é cristalino que o inquérito policial ao buscar os elementos indiciários e probatórios de um crime desempenha um importante papel no desempenho do Estado Democrático de Direito vigente na República Federativa do Brasil, uma vez que a prevenção e repressão de crimes visa a tutela de bens jurídicos 
protegidos pela lei penal que são, em sua essência, direitos fundamentais protegidos pela nossa Constituição.

Sobre a presidência do inquérito policial, o autor Aury Lopes Jr (2015, p. 116/117) explica que

Como determina o art. $4^{\circ}$ do CPP e o próprio nome indica, o inquérito é realizado pela polícia judiciária. Essa foi, desafortunadamente, a opção mantida pelo legislador de 1941, justificada na Exposição de Motivos como o modelo mais adequado à realidade social e jurídica daquele momento. Sua manutenção era, segundo o pensamento da época, necessária, atendendo às grandes dimensões territoriais e às dificuldades de transporte. Foi rechaçado o sistema de instrução preliminar judicial, ante a impossibilidade de que o juiz instrutor pudesse atuar de forma rápida nos mais remotos povoados, e grandes distâncias dos centros urbanos, e que às vezes exigiam vários dias de viagem.

Pelo o que foi exposto acima, verifica-se que, substancialmente, desde a vigência do Código de Processo Penal em 1941, é de incumbência da polícia judiciária, que no Brasil é de atribuição da Polícia Federal quando pertinente à União, conforme disposições do artigo 144, § 1ํㅡㄴ, IV, da CRFB, e da Polícia Civil de modo residual, de acordo com o artigo art. 144, $\S 4^{\circ}$, da CRFB.

Como estamos tratando de prerrogativa de foro de autoridades, especialmente sobre àqueles com prerrogativa de foro no Supremo Tribunal Federal, há interesse da União e, portanto, a instituição foco de nossa análise é a Polícia Federal.

Sobre as possíveis medidas e diligências possíveis a se proceder através do inquérito policial para a busca dos indícios de autoria e prova de materialidade, o autor Fernando da Costa Tourinho Filho (2009, p. 200) leciona que:

[...] o inquérito policial visa à apuração da existência de infração penal e à respectiva autoria, a fim de que o titular da ação 
penal disponha de elementos que o autorizem a promove-la. Apurar infração penal é colher informações a respeito do fato criminoso. Para tanto, a Polícia Civil desenvolve laboriosa atividade, ouvindo testemunhas que presenciaram o fato ou que dele tiveram conhecimento por ouvirem de outrem, tomando declarações da vítima, procedendo a exames de corpo de delito, exames de instrumento do crime, determinando buscas e apreensões, acareações, reconhecimentos, ouvindo o indiciado, colhendo informações sobre todas as circunstâncias que circunvolveram o fato tido como delituoso, buscando tudo, enfim, que possa influir no esclarecimento do fato [...]

Para a prevenção e repressão de crimes, a Polícia Federal tem o poder de instaurar o devido inquérito policial com a finalidade de reunir elementos probatórios através de oitivas de testemunhas, vítimas, interrogatórios de investigados, exames de corpo de delito, exames diversos sobre os instrumentos e proveitos do crime, buscas e apreensões, interceptações, quebras de sigilo, dentre outras possibilidades pertinentes a elucidação de fatos e tutela de direitos fundamentais de ofendidos, inclusive relativos à administração pública que representa os interesses da sociedade brasileira.

Para elucidar profundamente a justificativa da existência do inquérito policial e sua pertinência ao Estado Democrático de Direito previsto em nossa Constituição, os autores Aury Lopes Jr. e Ricardo Jacobsen Gloeckner (2013, p. 34) relatam que:

A titularidade do poder de punir por parte do Estado surge no momento em que é suprimida a vingança privada e são implantados os critérios de Justiça. O Estado, como ente jurídico e político, avoca para si o direito (e também o dever) de proteger a comunidade e, inclusive, o próprio delinquente como meio de cumprir sua função de procurar o bem comum, que se veria afetado pela transgressão da ordem jurídico-penal, por causa de uma conduta delitiva.

À medida que o Estado se fortalece consciente dos perigos que 
encerra a autodefesa, assumirá o monopólio da Justiça, produzindo-se não só a revisão da natureza contratual do processo, senão a proibição expressa para os particulares de tomarem a Justiça por suas próprias mãos. Diante da violação de um bem juridicamente protegido, não cabe outra atividade que não a invocação da devida tutela jurisdicional. Impõe-se a necessária utilização da estrutura preestabelecida pelo Estado - o processo judicial - em que, mediante a atuação de um terceiro imparcial, cuja designação não corresponde à vontade das partes e resulta da imposição da estrutura institucional, será solucionado o conflito e sancionado o autor. $O$ processo, como instituição estatal, é a única estrutura que se reconhece como legítima para a imposição da pena.

O Estado detém o monopólio da realização da Justiça e os particulares não podem por sua conta realizar seus anseios por suas próprias mãos para solucionar seus conflitos penais. Neste contexto, surge o inquérito policial com o objetivo de obedecer aos direitos e garantias fundamentais na apuração e julgamento de crimes, para se possibilitar uma pena justa que venha a prevenir e reprimir condutas, além de ressocializar o agente infrator.

Para se compreender a importância do trabalho da polícia judiciária na presidência dos inquéritos policiais, esclarecedora é a lição de Aury Lopes Jr. e Ricardo Jacobsen Gloeckner (2013, p. 129) para elucidar o modelo adotado no território brasileiro, conforme citação a seguir:

Não há dúvida de que a polícia tem condições de atuar em qualquer rincão do país, desde os grandes centros até os povoados mais afastados e isolados. Isso confere, principalmente, em países de grandes dimensões territoriais, como o Brasil, uma nota de efetividade da persecução, pois a polícia está em todos os lugares. Definitivamente, sua abrangência é maior que a dos juízes de instrução ou dos promotores de investigação.

Esse foi o principal argumento do legislador brasileiro de 1941 para justificar a permanência do inquérito policial, 
pois, segundo o pensamento da época, era o modelo mais adequado à realidade e às grandes dimensões territoriais de nosso país. Naquele momento, foi rechaçada a instrução preliminar judicial pela impossibilidade de que o juiz de instrução pudesse atuar de forma rápida nos mais remotos povoados, que, naquela época, exigiam vários dias de viagem.

Diante da grande extensão territorial brasileira, inclusive de sua longa faixa fronteiriça e muitos povoados esparsos, o Estado aparelhou e instrumentalizou a polícia judiciária para melhor atender e investigar com minúcia e propriedade a ocorrência de crimes.

Os Ministérios Públicos, ainda que legitimados pela Constituição, em sua maioria não foram até o momento preparados instrumentalmente para a realização plena de investigações criminais em campo e, do mesmo modo, os tribunais superiores não foram aparelhados para o curso de instruções processuais para o julgamento de crimes.

Diante da regra da prerrogativa de foro, ficou claro no segundo capítulo que as investigações e julgamentos de autoridades diplomadas somente ocorrerão perante os tribunais competentes, garantia esta que tem o risco de prejudicar o curso dos inquéritos policiais, e por consequência, o Estado Democrático de Direito, o que será verificado no próximo capítulo.

\section{O Foro por Prerrogativa de Função e Possíveis Prejuízos Às Investigações Criminais}

Para se avaliar se o foro por prerrogativa de função pode representar eventuais prejuízos às investigações criminais, importante avaliarmos qual é o atual entendimento jurisprudencial sobre a matéria, bem como a compreensão sobre como se operacionaliza o curso dos procedimentos administrativos e judiciais em face das autoridades que a princípio praticaram crime. 
É de suma importância relacionar ambos os institutos, quais sejam o foro por prerrogativa de função e o inquérito policial, com algumas das finalidades do Estado Democrático de Direito. Conforme já pacificado na presente pesquisa, o foro privilegiado busca a proteção das autoridades ocupantes de função públicas contra arbitrariedades jurídicas de cunho político por parte do próprio Estado, enquanto o inquérito policial desempenha relevante papel na tutela de direitos fundamentais ao prevenir e reprimir crimes na busca de indícios de autoria e prova de materialidade para a imposição de uma pena adequada.

Nesse passo, no que diz respeito ao entendimento jurisprudencial dominante quanto ao procedimento a ser adotado na hipótese de investigação de alguma autoridade com prerrogativa de foro, temos uma divergência jurisprudencial entre o Supremo Tribunal Federal e o Superior Tribunal de Justiça.

Primeiramente, importante o entendimento do Supremo Tribunal Federal (2018) sobre a matéria no julgamento do Inq 2411 QO publicado em 2008:

EMENTA: Questão de Ordem em Inquérito. 1. Trata-se de questão de ordem suscitada pela defesa de Senador da República, em sede de inquérito originário promovido pelo Ministério Público Federal (MPF), para que o Plenário do Supremo Tribunal Federal (STF) defina a legitimidade, ou não, da instauração do inquérito e do indiciamento realizado diretamente pela Polícia Federal (PF). 2. Apuração do envolvimento do parlamentar quanto à ocorrência das supostas práticas delituosas sob investigação na denominada "Operação Sanguessuga". 3. Antes da intimação para prestar depoimento sobre os fatos objeto deste inquérito, o Senador foi previamente indiciado por ato da autoridade policial encarregada do cumprimento da diligência.4. Considerações doutrinárias e jurisprudenciais acerca do tema da instauração de inquéritos em geral e dos inquéritos originários de competência do STF: i) a jurisprudência do STF é pacífica no sentido de que, 
nos inquéritos policiais em geral, não cabe a juiz ou a Tribunal investigar, de ofício, o titular de prerrogativa de foro; ii) qualquer pessoa que, na condição exclusiva de cidadão, apresente "notitia criminis", diretamente a este Tribunal é parte manifestamente ilegítima para a formulação de pedido de recebimento de denúncia para a apuração de crimes de ação penal pública incondicionada. Precedentes: INQ no 149/ DF, Rel. Min. Rafael Mayer, Pleno, DJ 27.10.1983; INQ (AgR) no 1.793/DF, Rel. Min. Ellen Gracie, Pleno, maioria, DJ 14.6.2002; PET - AgR - ED no 1.104/DF, Rel. Min. Sydney Sanches, Pleno, DJ 23.5.2003; PET no 1.954/DF, Rel. Min. Maurício Corrêa, Pleno, maioria, DJ 1ํ.8.2003; PET (AgR) no 2.805/DF, Rel. Min. Nelson Jobim, Pleno, maioria, DJ 27.2.2004; PET no 3.248/DF, Rel. Min. Ellen Gracie, decisão monocrática, DJ 23.11.2004; INQ no 2.285/ DF, Rel. Min. Gilmar Mendes, decisão monocrática, DJ 13.3.2006 e PET ( $A g R$ ) no 2.998/MG, $2^{a}$ Turma, unânime, DJ 6.11.2006; iii) diferenças entre a regra geral, o inquérito policial disciplinado no Código de Processo Penal e o inquérito originário de competência do STF regido pelo art. 102, I, b, da CF e pelo RI/STF. A prerrogativa de foro é uma garantia voltada não exatamente para os interesses do titulares de cargos relevantes, mas, sobretudo, para a própria regularidade das instituições. Se a Constituição estabelece que os agentes políticos respondem, por crime comum, perante o STF (CF, art. 102, I, b), não há razão constitucional plausível para que as atividades diretamente relacionadas à supervisão judicial (abertura de procedimento investigatório) sejam retiradas do controle judicial do STF. A iniciativa do procedimento investigatório deve ser confiada ao MPF contando com a supervisão do Ministro-Relator do STF. 5. A Polícia Federal não está autorizada a abrir de ofício inquérito policial para apurar a conduta de parlamentares federais ou do próprio Presidente da República (no caso do STF). No exercício de competência penal originária do STF (CF, art. 102, I, " $b$ " c/c Lei $n^{\circ}$ 8.038/1990, art. 2o e RI/STF, arts. 230 a 234), a atividade de supervisão judicial deve ser constitucionalmente desempenhada durante toda a tramitação das investigações desde a abertura dos procedimentos investigatórios até 
o eventual oferecimento, ou não, de denúncia pelo dominus litis. 6. Questão de ordem resolvida no sentido de anular o ato formal de indiciamento promovido pela autoridade policial em face do parlamentar investigado.

A jurisprudência do STF proíbe a Polícia Federal, ao tomar conhecimento de algum crime, a instauração de oficio do pertinente inquérito policial para apuração dos fatos. A Suprema Corte exige que, existindo indícios de autoria da prática de algum delito por uma autoridade com prerrogativa em seu tribunal, a PF ou Ministério Público Federal deve, imediatamente, provocar o tribunal para que seja autorizada a instauração de investigação criminal em face da autoridade com prerrogativa. A justificativa dos Ministros para sustentar o posicionamento se dá no sentido de que cabe ao tribunal competente a supervisão judicial prevista constitucionalmente durante toda a tramitação da investigação, funcionamento como um juízo de garantia. Portanto, o Supremo Tribunal Federal exige a sua autorização para a possibilidade de instauração de investigação criminal contra uma autoridade com foro privilegiado.

Em contrapartida, o Superior Tribunal de Justiça (2018) no julgamento RHC 59.563/MA em 2018, adotou a seguinte linha de interpretação sobre a mesma matéria:

RECURSO ORDINÁRIO EM HABEAS CORPUS. FRAUDE À LICITAÇÃO. PROCEDIMENTO INVESTIGATÓRIO INSTAURADO PELO MINISTÉRIO PÚBLICO. ENVOLVIMENTO DE AUTORIDADE COM FORO POR PRERROGATIVA DE FUNÇÃO. PRÉVIA AUTORIZAÇÃO DO PODER JUDICIÁRIO. DESNECESSIDADE. AUSÊNCIA DE PREVISÃO LEGAL.

VIOLAÇÃO AO SISTEMA ACUSATÓRIO. SUPERVISÃO DO PROCESSO PELA AUTORIDADE JUDICIAL COMPETENTE. COAÇÃO ILEGAL INEXISTENTE.

DESPROVIMENTO DO RECLAMO. 
1. No julgamento do REsp 1.563.962/RN, esta colenda Quinta Turma firmou o entendimento de que, embora as autoridades com prerrogativa de foro devam ser processadas perante o tribunal competente, a lei não excepciona a forma como devem ser investigadas, devendo ser aplicada, assim, a regra geral prevista no artigo $5^{\circ}$ do Código de Processo Penal.

2. Na ocasião, esclareceu-se que a jurisprudência tanto do Pretório Excelso quanto deste Sodalício é assente no sentido da desnecessidade de prévia autorização do Judiciário para a instauração de inquérito ou procedimento investigatório criminal contra agente com foro por prerrogativa de função, dada a inexistência de norma constitucional ou infraconstitucional nesse sentido, conclusão que revela a observância ao sistema acusatório adotado pelo Brasil, que prima pela distribuição das funções de acusar, defender e julgar a órgãos distintos.

3. No caso dos autos, conquanto o recorrente, então Prefeito Municipal, tenha sido diretamente investigado pelo Ministério Público, o procedimento apuratório foi acompanhado por Desembargador do Tribunal de Justiça do Estado do Maranhão, que, inclusive, exerceu o controle jurisdicional sobre os atos nele praticados, deferindo, por exemplo, o pedido de busca e apreensão formulado pelo órgão ministerial, não havendo que se falar, assim, em ofensa à prerrogativa de foro prevista no inciso X do artigo 29 da Constituição Federal. Precedentes.

INSTAURAÇÃO DE PROCEDIMENTO INVESTIGATÓRIO CRIMINAL. ELEMENTOS DE CONVICÇÃO COLHIDOS PELO MINISTÉRIO PÚBLICO. POSSIBILIDADE. ILICITUDE NÃO CARACTERIZADA.

1. O Supremo Tribunal Federal, no julgamento do RE 593.727/MG, analisado sob o regime de repercussão geral, reconheceu a legitimidade do Ministério Público para promover, por autoridade própria, procedimentos investigatórios de natureza penal.

2. Dessa forma, nada impede que o órgão ministerial colha 
elementos de convicção para subsidiar a propositura de ação penal, exatamente como ocorreu na espécie, só the sendo vedada a presidência do inquérito, que compete exclusivamente à autoridade policial.

\section{Recurso desprovido.}

Pelo o que foi exposto acima, verificou-se que o STJ diverge quanto ao entendimento do STF sobre a possibilidade de investigação criminal direta pelos órgãos com atribuição sem a permissão dos tribunais competentes para julgamento das autoridades com foro por prerrogativa.

Na hipótese de investigação criminal em face de autoridade com foro privilegiado, o Superior Tribunal de Justiça dispensa a autorização do tribunal competente para a instauração de inquérito policial e permite que seja feita de ofício pelos órgãos de investigação. A corte justifica o seu entendimento ao dizer que a Constituição apenas abrange no foro por prerrogativa de função o que diz respeito ao processamento do feito para julgamento, ou seja, pertinente à ação penal propriamente dita. No que tange às investigações criminais, os Ministros denunciam um silêncio eloquente da norma constitucional prevendo a prerrogativa nesta fase, e, desta forma, utilizam, para tanto, a regra do art. $5^{\circ}$ do $\mathrm{CPP}$, ressaltando-se, ainda, o respeito ao sistema acusatório.

Diante das ideias lançadas acima, pacificou-se o entendimento no STJ de que é desnecessária a prévia autorização do tribunal competente para a instauração do inquérito, o procedimento investigatório criminal contra agente com foro por prerrogativa de função, uma vez que inexiste norma constitucional ou infraconstitucional tratando a matéria, além do respeito ao sistema acusatório consagrado em nossa Constituição.

Concordamos com o posicionamento do Superior Tribunal de Justiça, pois além de se privilegiar a autonomia do sistema 
acusatório no direito brasileiro, também garantimos uma investigação veloz, sigilosa e possivelmente mais eficaz quando realizada, originariamente e unilateralmente pela Polícia Federal, sem a comunicação ao tribunal superior.

Entretanto, com relação à exigência do Supremo Tribunal Federal em exigir a sua provocação para a autorização da investigação, não vemos qualquer prejuízo igualmente para as investigações, pois o tribunal superior apenas realizará um juízo de garantia em favor da autoridade investigada, diante da importância de sua função desempenhada no serviço público brasileiro, a qual deve ser protegida contra arbitrariedades.

Sobre este papel desempenhado pelo Poder Judiciário, vemos a sua materialização a partir do posicionamento de Aury Lopes Jr. e Ricardo Jacobsen Gloeckner (2013, p. 260) os quais afirmam que:

A atuação do juiz na fase pré-processual (seja ela de inquérito policial, investigação pelo MP etc.) é e deve ser por muito limitada. O perfil ideal do juiz não é como investigador ou instrutor, mas como controlador da legalidade e garantidor do respeito aos direitos fundamentais do sujeito passivo. Nesse sentido, além de ser uma exigência do garantismo, é também a posição mais adequada aos princípios que orientam o sistema acusatório e a própria estrutura dialética do processo penal.

Os magistrados dos tribunais exercem simplesmente um papel de controle de legalidade e garantia de observância dos direitos fundamentais da autoridade investigada, exercendo um juízo qualificado de garantismo, não podendo atuar como investigador ou instrutor da investigação. Notamos que o STF apenas exige a sua vênia para início da investigação e jurisdição sobre todas as medidas restritivas judiciais pertinentes ao inquérito policial, como, por exemplo, uma busca e apreensão ou interceptação telefônica. 
O grande problema que constatamos realmente sobre a foro por prerrogativa de função está na fase judicial de processamento das ações penais pertinente às autoridades com prerrogativa de foro, uma vez que o instituto muitas vezes é desvirtuado e utilizado como um salvo-conduto para o cometimento de crimes e um bilhete para se conseguir prescrições e privilégios processuais indevidos.

O Juiz Federal Marcio André Lopes Cavalcante (2018) traz importantes críticas funcionais e práticas ao instituto quando instaurada a devida ação penal, ao afirmar que:

Este modelo amplo de foro por prerrogativa de função tradicionalmente adotava acarreta duas consequências graves e indesejáveis para a justiça e para o STF:

1a) Afasta o Tribunal do seu verdadeiro papel, que é o de Suprema Corte, e não o de tribunal criminal de primeiro grau. Tribunais superiores, como o STF, foram concebidos para serem tribunais de teses jurídicas, e não para o julgamento de fatos e provas. Como regra, o juízo de primeiro grau tem melhores condições para conduzir a instrução processual, tanto por estar mais próximo dos fatos e das provas, quanto por ser mais bem aparelhado para processar tais demandas com a devida celeridade, conduzindo ordinariamente a realização de interrogatórios, depoimentos, produção de provas periciais etc.

$2^{a}$ ) Contribui para a ineficiência do sistema de justiça criminal. O STF não tem sido capaz de julgar de maneira adequada e com a devida celeridade os casos abarcados pela prerrogativa. O foro especial, na sua extensão atual, contribui para o congestionamento dos tribunais e para tornar ainda mais morosa a tramitação dos processos e mais raros os julgamentos e as condenações.

Primeiramente, é alertado que o STF não tem o devido aparelhamento e estrutura para se processar uma ação penal que substancialmente é preparada para o tratamento de um juízo 
de primeiro grau. Acrescenta, ainda, nesta primeira observação, que a Suprema Corte está preparada para analisar simplesmente teses jurídicas e não instruir processos criminais, o que demanda um grande esforço, tempo e estrutura que não está à sua disposição. Além disso, também denuncia a grande demanda do Supremo Tribunal Federal para o julgamento de demandas, o que torna moroso o procedimento e consequente congestionamento do tribunal competente.

A crítica realizada acima é coerente a partir de uma simples leitura da Lei 8.038/90 que trata sobre as normas procedimentais do STF e STJ. O procedimento ali previsto não está adequado ao propósito e estrutura vista nos referidos tribunais, o que torna moroso e ineficaz o processo criminal das autoridades com prerrogativa de foro. Tal condição faz o instituto ser desvirtuado para uma condição processual privilegiada apenas para o alcance de prescrições e privilégios inadequados em julgamentos muitas vezes pressionados pela opinião pública e poder político, o que fere de modo vertiginoso a isonomia entre os indivíduos, pretendida também pelo nosso Estado Democrático de Direito.

Com relação à isonomia aqui levantada entre todos os indivíduos sujeitos à jurisdição brasileira, sabemos que o direito penal aqui aplicado é o direito penal do fato e não o direito penal do autor, o que se desvirtua dos efeitos práticos do foro privilegiado, pois ele acaba diferenciando de modo qualificado autoridades em detrimentos dos demais cidadãos.

No que toca à existência, nos tempos atuais, do foro por prerrogativa de função, o professor Guilherme de Souza Nucci (2017, p. 215) realiza severas críticas quanto ao seu modo de funcionamento:

Não vemos motivo suficiente para que o Prefeito seja julgado na Capital do Estado, nem para que o juiz somente possa sê-lo pelo Tribunal de Justiça ou o desembargador pelo Su- 
perior Tribunal de Justiça e assim por diante. Se à Justiça Cível todos prestam contas igualmente, sem qualquer distinção, natural seria que a regra valesse também para a Justiça Criminal. O fato de se dizer que não teria cabimento um juiz de primeiro grau julgar um Ministro de Estado que cometa um delito, pois seria uma "subversão de hierarquia" não é convincente, visto que os magistrados não são todos independentes e, no exercício de suas funções jurisdicionais, não se submetem a ninguém, nem há hierarquia para controlar o mérito de suas decisões. Logo, julgar um Ministro de Estado ou um cidadão qualquer exige do juiz a mesma imparcialidade e dedicação, devendo-se clamar pelo mesmo foro, levando em conta o lugar do crime e não a função do réu.

O autor aponta que o foro por prerrogativa de função nos tempos atuais é inadequado por causar danos à isonomia dos indivíduos quando se prevê um tribunal especializado para o seu julgamento. Afirma, ainda, que todos os magistrados de $1^{\underline{0}}$ (primeiro) grau possuem a mesma imparcialidade e dedicação de um ministro ou desembargador de tribunal, devendo se levar em conta o lugar do crime para a fixação de competência e não para a função desempenhada pelo réu.

O mesmo Guilherme de Souza Nucci (2017, p. 215) corrobora suas ideias ao acrescentar que:

[...] a autoridade julgada pelo magistrado de $1^{\circ}$. Grau sempre pode recorrer, havendo ou não equívoco na decisão, motivo pelo qual é incompreensível que o foro privilegiado mantenha-se no Brasil. Por que não haveria sentido, como muitos afirmam, que um juiz julgasse um Ministro do Supremo Tribunal Federal? Não está julgando o cargo, mas sim a pessoa que cometeu um delito. Garantir que haja o foro especial é conduzir justamente o julgamento para o contexto do cargo e não do autor da infração penal. Por acaso teria o judiciário maior zelo para condenar um Presidente da República do que um brasileiro comum? Pensamos que jamais deveria agir como tal postura discriminatória, o que justifica deverem todos ser jul- 
gados pelo magistrado do lugar da infração ou do domicílio do réu, executados apenas os casos de matérias específicas.

Contra o argumento sobre o estabelecimento de um juízo mais qualificado nos tribunais superiores aos detentores de foro por prerrogativa de função, é realizado um raciocínio lógico de que, caso não existisse referida garantia, as autoridades - caso fossem julgadas criminalmente pelo juízo de primeiro grau -, de qualquer modo, poderiam recorrer em segundo grau até referidos tribunais por força do duplo grau de jurisdição, ou seja, somente seriam condenados ou não, por equívoco ou não, após o conhecimento e cognição dos ministros ou desembargadores.

O foro por prerrogativa de função nos tempos atuais em que a democracia está distante de regimes autoritários ou totalitários, pode representar a quebra da isonomia em face dos demais brasileiros e um verdadeiro privilégio indevido para se conseguir a impunidade, haja vista a morosidade da instrução dos processos e julgamentos nos órgãos colegiados competentes, além da circunstância de que a autoridade na maioria das vezes perde o segundo grau de jurisdição, salientando-se que estamos diante do direito penal do fato e não do autor.

Ainda que o instituto do foro por prerrogativa de função não tenha a mesma necessidade que possuía na promulgação da Constituição de 1988, pois saíamos de um regime totalitário para mergulharmos num Estado Democrático de Direito, notamos que as investigações criminais não são prejudicadas, uma vez que a exigência atual do STF é apenas um juízo qualificado de garantias, o que não prejudica o curso, sigilo e eficácia das investigações. Ressalte-se que o entendimento do STJ, que dá autonomia às policiais judiciárias e aos ministérios públicos na instauração de ofícios dos inquéritos policiais em face das autoridades protegidas pelo foro privilegiado, está mais adequado ao sistema acusatório previsto em nossa Constituição. O prejuízo existe e é 
patente à instrução e julgamento das ações penais, haja vista o despreparo estrutural e desvirtuamento funcional dos tribunais de jurisdição superior brasileiros.

Portanto, pelo o que foi exposto no presente capítulo, o ideal é caminharmos para o fim do foro por prerrogativa de função, seja por mutação constitucional na forma que está sendo realizada pelo STF no julgamento da questão de ordem relativa à AP 937 que impôs restrições ao foro privilegiado para atos relacionados com as funções de deputados e senadores, ou seja por meio de emenda constitucional, uma vez que a igualdade prevista em nossa Carta Magna deve se manifestar também em relação aos órgãos competentes para investigação, processo e julgamento.

\section{Conclusão}

A pesquisa se deu sobre a pertinência do foro por prerrogativa de função no Estado Democrático de Direito e suas consequências sobre as investigações criminais, identificando-se eventuais prejuízos aos inquéritos policiais pertinentes ao conhecimento dos indícios de autoria e prova de materialidade de crimes cometidos por autoridades protegidas pelas regras previstas em nossa Constituição.

O primeiro objeto de investigação da pesquisa foi a compreensão do instituto do foro por prerrogativa de função e a sua correlação com o Estado Democrático de Direito previsto no art. $1^{\text {o }}$ da CRFB. Concluímos que o foro privilegiado, após décadas de arbitrariedades praticadas em regime ditatorial que perdurou no Brasil, foi positivado para garantir a proteção e liberdade funcional das autoridades contra perseguições jurídicas de cunho político, condição necessária para a saúde da República Federativa do Brasil, espiritualizada no constituinte de 1988. 
No segundo capítulo, conseguimos aprofundar a pesquisa sobre o instituto do Estado Democrático de Direito, na intenção de avaliar alguma pertinência sobre os reflexos processuais penais e materiais do foro por prerrogativa de função aos seus propósitos, assim como conseguimos obter a relação direta de seus anseios ao instrumento do inquérito policial previsto em nosso Código de Processo Penal. É objetivo do Estado brasileiro a tutela de direitos fundamentais, o que é possível através da prevenção de repressão de crimes que devem ser investigados para a sua apuração, solução e tutela de bens jurídicos. Tal entendimento foi corroborado no capítulo seguinte, destacandose a importância de a investigação criminal ser realizada pela polícia judiciária diante das características territoriais do Brasil e das características de aparelhamento e estruturação das policiais judiciárias, ministérios públicos e tribunais superiores, privilegiando-se os órgãos policiais para a realização de diligências investigatórias, haja vista a magnitude de sua estrutura técnica, física e corpo pessoal.

No último capítulo, analisamos os entendimentos jurisprudenciais firmados pelo Supremo Tribunal Federal e Superior Tribunal de Justiça, assim como entendimentos doutrinários críticos ao foro por prerrogativa de função no Brasil.

Após o referido estudo, constatamos que o foro privilegiado não prejudica as investigações criminais, uma vez que a exigência atual do STF em autorizar a instauração do inquérito policial contra a autoridade representa simplesmente um juízo qualificado de garantias, condição que não prejudica o curso, sigilo e eficácia das investigações. Portanto, não há prejuízos ao nosso Estado Democrático de Direito. Ressalte-se que o entendimento do STJ em dar autonomia às policiais judiciárias e aos ministérios públicos na instauração de ofícios dos inquéritos policiais em face das autoridades protegidas pelo foro privile- 
giado, está mais adequado ao sistema acusatório previsto em nossa Constituição.

Entretanto, embora não seja o problema central de nossa investigação, não podemos ignorar o fato de que não há a mesma necessidade de existência em, nosso ordenamento jurídico, do foro por prerrogativa de função, este que era de fato imprescindível na promulgação da Constituição de 1988, pois saíamos de um regime totalitário para um Estado Democrático de Direito.

Além dessa constatação, verificamos, também, que o foro privilegiado causa danos à instrução e julgamento das ações penais das autoridades abarcadas, haja vista o despreparo estrutural e o desvirtuamento funcional dos tribunais de jurisdição superior brasileiros, condição esta que atualmente causa prejuízos ao Estado Democrático de Direito, pois direitos fundamentais que são bens jurídicos tutelados pela norma penal não são protegidos diante da impunidade das autoridades infratoras, quebrando assim a isonomia com os demais brasileiros não detentores de cargo, salientando-se que estamos diante do direito penal do fato e não do autor.

Por todo o exposto, o ideal é caminharmos para o fim do foro por prerrogativa de função, seja por mutação constitucional na forma que está sendo realizada pelo STF no julgamento da questão de ordem relativa à AP 937 que impôs restrições ao foro privilegiado para atos relacionados com as funções de deputados e senadores, ou por meio de emenda constitucional, uma vez que a igualdade prevista em nossa Carta Magna deve se manifestar também em relação aos órgãos competentes para investigação, processo e julgamento. 


\section{REFERÊNCIAS}

BITENCOURT, Cezar Roberto. Tratado de Direito Penal. 22ª ed. São Paulo: Saraiva, 2016.

BRASIL. Constituição da República Federativa do Brasil de 1988.

Disponível em: <http://www.planalto.gov.br/ccivil_03/ constituicao/constituicaocompilado.htm>. Acesso em 5.jun.2018.

BRASIL. Lei 8.038 de 28 de Maio de 1990. Disponível em: <http:// www.planalto.gov.br/ccivil_03/Leis/L8038.htm>. Acesso em 5.jun.2018. . Superior Tribunal de Justiça. RHC 59.593/MA, Relator(a): Min. JORGE MUSSI, QUINTA TURMA, julgado em 19/04/2018, DJe 27/04/2018.

- Supremo Tribunal Federal. Acórdão no Inq 2411 QO. Relator: GILMAR MENDES. Tribunal Pleno, julgado em 10/10/2007, DJe-074 DIVULG 24-04-2008 PUBLIC 25-042008 EMENT VOL-02316-01 PP-00103 RTJ VOL-00204-02 PP-00632).

BULOS, Uadi Lâmego. Curso de Direito Constitucional. 11ª ed. São Paulo: Saraiva, 2017.

CARVALHO, Kildare Gonçalves. Direito Constitucional: Teoria do Estado e da Constituição; Direito Constitucional Positivo. Belo Horizonte: Del Rey, 2008.

CAVALCANTE, Marcio André Lopes. Foro por Prerrogativa de Função: Panorama Atual. Disponível em: <https://www. dizerodireito.com.br/2018/06/foro-por-prerrogativa-defuncao.html>. Acesso em: 26 jun. 2018.

FERNANDES, BernardoGonçalves. Curso de Direito Constitucional. 3.ed. Rio de Janeiro: Lumen Juris, 2011. 
FILHO, Fernando da Costa Tourinho. Processo Penal. 31. ed. São Paulo: Saraiva, 2009.

JUNIOR, Aury Lopes. Direito Processual Penal. 12aㅡ ed. São Paulo: Saraiva, 2015.

JUNIOR, Aury Lopes; GLOECKNER, Ricardo Jacobsen. Investigação Preliminar no Processo Penal. $5^{\mathbf{a}}$ ed. São Paulo: Saraiva, 2013.

LIMA, Renato Brasileiro de. Manual de Processo Penal. 2a ed. Salvador: Juspodivm, 2014.

MENDES, Gilmar Ferreira; BRANCO, Paulo Gustavo Gonet. Curso de Direito Constitucional. 12 a ed. São Paulo: Saraiva, 2017.

MORAES, Alexandre de. Direitos Humanos Fundamentais: teoria geral, comentários aos arts. $1^{\circ}$ ao $5^{\underline{o}}$ da Constituição da República Federativa do Brasil, doutrina de jurisprudência. 8. ed. São Paulo: Atlas, 2007.

MORAES, Alexandre de. Direito Constitucional. 31ํㅗ ed. São Paulo: Atlas, 2015.

NOVELINO, Marcelo. Manual de Direito Constitucional. 9ª̣ed. São Paulo: Método, 2014.

NUCCI, Guilherme de Souza. Manual de Processo Penal e Execução Penal. 11 $1^{\mathrm{a}}$ ed. Rio de Janeiro: Forense, 2014.

OLIVEIRA, Eugênio Pacelli. Curso De Processo Penal. 20ª ed. - São Paulo: Atlas, 2016.

SARLET, Ingo Wolfgang; MARINONI, Luiz Guilherme; MITIDIERO, Daniel. Curso de Direito Constitucional. São Paulo: Saraiva, 2017.

TAVARES, André Ramos. Curso de Direito Constitucional. 15ª ed. São Paulo: Saraiva, 2017. 
